\title{
A symbolic annotation of vowel sounds for emerging readers
}

Patrick M. Donnelly ${ }^{1,2}$, Liesbeth Gijbels ${ }^{1,2}$, Kevin Larson³, Tanya Matskewich³, Paul Linnerud³, Patricia K. Kuhl $^{1,2} \&$ Jason D. Yeatman ${ }^{4,5}$

1. University of Washington, Institute for Learning \& Brain Science, Seattle, WA, USA

2. University of Washington, Department of Speech \& Hearing Sciences, Seattle, WA, USA

3. Microsoft Corporation, Redmond, Washington, USA

4. Stanford University, School of Medicine, Division of Developmental-Behavioral Pediatrics, Stanford, CA, USA

5. Stanford University, Graduate School of Education, Stanford, CA, USA

Corresponding author: Patrick M. Donnelly - pdonne@uw.edu

\begin{abstract}
:
Research on educational technologies for reading instruction is disproportionate to the myriad applications in the marketplace. Here we assess a web-based reading tool, Sound it Out, that assists struggling readers in decoding by annotating vowels with small icons indicating the associate phoneme. Created as a collaboration between researchers and technology developers, the phonemic-image cue was designed to scaffold letter-sound correspondence. Study 1 examined whether Sound it Out provides an immediate benefit to reading performance in thirty struggling readers (ages 8-10) randomly assigned to counterbalanced groups in a single-session. Results showed that, without a period of practice, children were not able to capitalize on the cues for improved text reading. Study 2 utilized a repeated measures randomized controlled trial design to determine if an extended practice period (1 month) produced gains and whether a caregiver supervised practice ("dyadic reading") enhanced benefits. Seventy-six struggling readers (ages 7-13) were randomly assigned to two intervention groups (independent and dyadic reading) and one control group. Results showed significant, dose-response benefits to decoding accuracy and passage reading accuracy for the combined intervention groups in comparison to controls. Moreover, supervised dyadic reading enhanced the effect of practice. These results
\end{abstract}


highlight the potential for an evidenced-based supplemental learning technology to support both independent and shared reading for struggling readers. 


\section{Introduction:}

Even before the COVID-19 pandemic, technology was ubiquitous in education. As schools went virtual, and education became inextricably linked to screens, there has been increased interest in educational technologies for reading instruction (Cassidy, Ortlieb, and Grote-Garcia 2020; Greenfield 2009; Wolf 2018; Zuckerman 2017). In their pivotal report, the National Reading Panel suggested that computers represent a promising opportunity for teaching reading (National Reading Panel 2000). Twenty years later, the marketplace for educational technologies for literacy is expansive (Guernsey and Levine 2015), and 'multimodal/digital literacy' is a priority for educators and researchers nationwide (Cassidy, Ortlieb, and Grote-Garcia 2020). There have been many promising and successful technologies, but the vast majority of educational technologies for literacy either lack a connection to evidence (Guernsey and Levine 2015; Christ, Arya, and Liu 2018), have small effect sizes (Cheung and Slavin 2011) or have not been studied empirically (Cheung and Slavin 2013; Stetter and Hughes 2015).

The problem, according to a recent meta-analysis, is the prevailing ideology that there is inherent 'magic' when machines enter the world of education (Cheung and Slavin 2013). Although these technologies are implemented at-scale, analyses reveal limited short- and long-term gains, small sample sizes and less rigorous designs (Grant et al. 2012; Blok et al. 2002; Stetter and Hughes 2015). However, juxtaposed with these findings, are consistent reports of the opportunity that exists for digital solutions for struggling readers (Soe, Koki, and Chang 2000; Cheung and Slavin 2013; Benton et al. 2014; Wolf et al. 2017; Hutchison, Beschorner, and Schmidt-Crawford 2012). Namely, researchers point to various aspects of technology that are ideally suited to the needs of emerging readers: technology provides seemingly limitless opportunities for practice and scaffolding (Soe, Koki, and Chang 2000; Ronimus and Lyytinen 2015; Campuzano et al. 2009), persistent and direct feedback (Richardson and Lyytinen 2014; Benton et al. 2018), and motivated, child-driven autonomy in the learning process (Wolf et al. 2014; Larson 2010; McTigue et al. 2020). Most poignantly, technology provides an opportunity to supplement classroom learning with individually-optimized material to support the development of foundational skills that a struggling reader requires (Grant et al. 2012; Hutchison, Beschorner, and Schmidt-Crawford 2012; Harris and Hofer 2009; Eagleton and Dobler 2007; Gee 2003; Soe, Koki, and Chang 2000; Barker 
and Torgesen 1995; Atkinson and Hansen 1966; Ok and Rao 2019; Taylor et al. 2020; Solheim et al. 2018).

A particularly successful application of technology targets the foundational skills of phonological awareness and letter-sound correspondence (Barker and Torgesen 1995; Torgesen et al. 2010; Abrami, Lysenko, and Borokhovski 2020). Phonics, or code-based, curricula are an essential component of evidence-based instruction (Seidenberg, Cooper Borkenhagen, and Kearns 2020; Petscher et al. 2020; Moats 1999; Castles, Rastle, and Nation 2018), and are particularly important for struggling readers (Wanzek et al. 2013; Vaughn et al. 2008; Maureen W. Lovett et al. 2017; Ehri et al. 2001). Due to a multitude of factors, ranging from disability and limited adoption of sciencebased reading practice in schools, struggling readers are often unable to access high-quality, iterative and targeted instruction in traditional classrooms (Seidenberg 2017; Hindman et al. 2020; Petscher et al. 2020). For this reason, many practitioners, advocates and families have turned to technology as means to tailor education to a reader's unique needs.

Sound it Out, the subject of the current work, was designed to address this need in providing a foundational tool to scaffold and empower emerging readers both at school and at home. Created with the Advanced Reading Technologies team at Microsoft, Sound it Out is a web-based application that is nested within the domain of educational technologies that focus on phonological awareness and letter-sound correspondence skill. For each vowel in a given text, the app utilizes a text-to-speech application programming interface (API) to access the corresponding image cue (e.g., a moon for /u/ in "through") that relates to common pronunciation in Standard American English. The image cue is placed underneath the printed vowel, as an annotation, and contains an auditory cue that is triggered with a click. So, when a reader comes to a challenging word, they have the ability to use both visual and auditory cues to determine the target vowel sound, or, with mastery, the visual cue alone or no cue at all. Sound it Out was designed in a collaborative effort between researchers at the University of Washington (UW) and Microsoft, and all testing was conducted independently by the UW laboratory to determine the legitimacy of the web-app for emerging readers. 
The pedagogical basis for the phonemic cue used in Sound it Out in reading instruction is well documented. For elementary educators, many evidence-based curricula use image cards and symbols to help scaffold letter/sound knowledge (Moats 1999). For example, Fundations, a part of the Wilson Language Training program, uses pictures to represent both consonants and vowel sounds (i.e. Apple for 'A', Bat for 'B', etc) (“Fundations ${ }^{\circledR}$ ” n.d.). Moreover, Vowel Alert is a component strategy of PHAST (for Phonological and Strategy Training), a well-studied phonics program, and similarly cues readers to try out vowel sounds to find the one that 'yields the correct word' (M. W. Lovett, Lacerenza, and Borden 2000). Thus, Sound it Out provides an on-demand synthetic phonics-based scaffold (Mandel Morrow and Asbury 1999) to aid readers in learning the complex and opaque orthographic representations of English vowels.

The research on digital applications of phonics strategies is reassuring: compared to more comprehensive classroom oriented technologies, supplemental programs that focus on alphabetic skills, explicit phonological awareness instruction, and phoneme sequencing are among the most effective programs for improving outcomes (Torgesen et al. 2010; Cheung and Slavin 2013). Of the supplemental programs that have shown promise, a few have stood out in their commitment to merge research and practice: Graphogame, Daisy Quest, Lexia and ROSS. Graphogame, a gamified, literacy app that has been implemented in many languages, works at the level of the sound to focus on synthetic phonics skills, rhyme, morphology, and orthography (Richardson and Lyytinen 2014). In using a gamified platform, Graphogame is able to produce high levels of motivation and engagement, both at school and at home (McTigue et al. 2020; Ronimus and Lyytinen 2015). Daisy Quest, another gamified project, provides a whimsical narrative to teach rhyme, onset-rime, and sound segmentation and has been associated with measurable gains in phonological awareness mastery (Barker and Torgesen 1995; Erickson et al. 1992). Lexia, a technology designed for school implementation, focuses on phonological strategies as well, but utilizes telemetry and tutorial-style learning to provide personalized and adaptive support (Macaruso, Hook, and McCabe 2006). Reading with Orthographic and Segmented Speech (ROSS), in contrast, provides various levels of segmentation - from phonemes to syllables to words - to help readers when they encounter challenging words in connected-text. In combination with an explicit phoneme manipulation program, ROSS not only provided measurable gains but also saw high levels of engagement and motivation in a population that is prone to feeling overwhelmed 
by passage-based learning (Wise and Olson 1995, 1998). Together, these and other programs provide unique methods for technology to enhance learning, but all adhere to the principle of implementation that a program's impact is dependent on its ability to help both students and teachers achieve their instructional goals (Lee et al. 2013).

In the same vein as Sound it Out, are educational technologies such as Trainertext and SeeWord Reading. Trainertext, developed by researchers and developers in the United Kingdom, provides visual mnemonics above each phoneme (vowels and consonants) to whimsically support shared reading with an adult. Results from a ten-month, longitudinal study reported significant benefits to measures of decoding and fluency (Messer and Nash 2018). SeeWord Reading, instead integrates a picture-embedded font to provide a symbolic scaffold for learning the alphabetic principle. Studies demonstrate that the application produces measurable gain in grapheme-phoneme consolidation (Seward et al. 2014). As digital siblings of Sound it Out, both Trainertext and SeeWord Reading reveal the validity of a tool that provides a symbolic image cue to assist emerging readers. Unique to Sound it $\mathrm{Out}$, is the versatility and flexibility it has to adapt to the variability in curricula for individual learners.

Additionally, providing phonemic annotations has been shown to be useful for emerging readers across different orthographies. In both Arabic and Hebrew, diacritic marks (pointed-scripts) are used to vowelize text for beginning readers (Mahfoudhi, Everatt, and Elbeheri 2011). This vowelization transforms the deep orthography of formal Arabic and Hebrew into a shallower orthography and allows readers to use a phonological code to gain familiarity with the more complex orthography (Abu-Rabia 1999, 2001; Schiff and Saiegh-Haddad 2018). As a result of using this phonological cue, phonological processing skills are highly predictive of reading performance for Arabic readers even as they transition to the non-vowelized formal orthography (Elbeheri and Everatt 2007). Akin to English, dyslexic Arabic children demonstrate a similar phonological deficit and pronounced difficulty with the vowelized script (Elbeheri and Everatt 2007). In terms of efficacy, studies have shown that early readers who have access to these pointed-scripts in Hebrew demonstrate greater accuracy in word reading (Haddad et al. 2018; Shany, Bar-On, and Katzir 2012), but that benefit decreases with age and reading proficiency (Schiff and Saiegh-Haddad 2018; Weiss, Katzir, and Bitan 2015b, [a] 2015). Benefits are conflicting 
for children with dyslexia (Weiss, Katzir, and Bitan 2015a), but few studies have explored auditory cues alongside pointed-scripts as an intervention tool. Related to the goals of Sound it Out, the use of diacritics in Proto Semitic languages provides a phonological bootstrap to both orthography and morphology (Elbeheri and Everatt 2007; Haddad et al. 2018).

A digital cue to scaffold vowel decoding during passage reading is also rooted in the concept of 'word learning in context' (Ehri 2014), a major tenet of blended theories of reading development. In line with the Interactive Strategies Approach, Sound it Out is an application of explicit phonics instruction in combination with word solving skills to incorporate 'interactive and confirmatory' strategies to approach novel words and build sight vocabulary (Vellutino and Scanlon 2002). As this theory suggests, Sound it Out uses a meaningful, engaging context to provide a code-based cue that will ensure long-term consolidation of sub-lexical units (i.e. vowels, syllables, morphemes) (Mesmer and Williams 2015). This is duly supported by the Phase Theory of Reading (Ehri 1995), which stipulates that "reading words in meaningful contexts ensures that syntactic and semantic identities of words become bonded to spellings and pronunciations to form amalgamated units in memory" (Ehri 2020). Fusing phonics and comprehension extends to the dynamic, reciprocal relations of the Lattice Model of reading development (Hindman et al. 2020; McDonald Connor et al. 2009), and the coordination of implicit and explicit statistical learning mechanisms in computational models (Seidenberg, Cooper Borkenhagen, and Kearns 2020; Seidenberg 2005; Share 1995; Coltheart et al. 2001). Sound it Out, then, is intended to provide readers a context to compare sources of information and a tool to focus attention on the information that will encourage long-term consolidation and learning: the alphabetic code (Scanlon and Anderson 2020; Ehri 2014).

Initial, proof-of-concept research into Sound it Out revealed limited, yet promising effects of the cue on reading performance (Donnelly et al. 2020). In a small-scale randomized controlled trial (RCT), with a short practice period (two-weeks), our research group found that the cue had a significant impact on pseudo word decoding but no significant impact on connected-text reading or real word decoding. The pseudoword decoding benefit was small - about two additional items read, on average - however, combined with qualitative survey data which demonstrated substantial interest and engagement, overall findings suggested that, with some modifications, 
this technology could represent a promising approach to supplement phonics based classroom instruction.

The present work builds on these initial findings to (a) hone the implementation of the technology and (b) test its efficacy under various use cases. Namely, this paper details two studies that aim to describe the conditions that are necessary for the cue to impact reading performance beyond single word decoding. Extending from our previous research that was ambiguous with regards to the effect of practice on cue benefit, Study 1 utilizes a single-session crossover design to determine if we can replicate our previous findings without the practice period. In other words, does the phonemic image provide an immediate benefit to reading? Because the Sound it Out cue was so easy to learn, we hypothesized that children could immediately use the cue to sound out difficult words that were above their reading level. Study 2, an RCT conducted one year later, employs a version of the app now powered by a speech API to answer two main questions: (1) Can an extended period of exposure produce proportional gains in reading skill? And (2) Can the benefit of the cue be enhanced by involving a parent/caregiver in the intervention (dyadic reading)? We hypothesized that an extended period of exposure would produce measurable gains and that the gain would be significantly pronounced in the dyadic reading condition. All data and analysis code is publicly available at https://github.com/yeatmanlab/sounditout public.

\section{Methods: Study 1}

\section{Participants}

Thirty-two children between 8 and 10 years old were recruited from the University of Washington (UW) Reading \& Dyslexia Research Program database, an online repository of families interested in reading research in Western Washington. Three participants withdrew from participation during the study, leaving a final dataset of twenty-eight (14 Female, 14 Male) participants. These participants were struggling readers, as characterized by performance on a standardized battery of reading assessments. In order to capture a heterogeneous sample the classification of 'struggling readers' was based on performance 1 SD below the standard norm on either the Woodcock-Johnson IV Test of Achievement Basic Reading Skills (WJ BRS) or the Test of Word 
Reading Efficiency-2 (TOWRE Index) composite measures, and above 1 SD below the mean on the Wechsler Abbreviated Scales of Intelligence Full Scale-2 (WASI FS2) composite measure. This was the same criteria as our previous work (Donnelly et al. 2020). Twenty participants had a diagnosis of developmental dyslexia. Participants were also assessed for phonological processing using the Comprehensive Test of Phonological Processing - 2 (CTOPP), but that test was not used as an enrollment criteria. Participants were screened previously for potential speech/language/hearing disorders, neurological impairments, and psychiatric disorders. Due to high co-occurrence with ADHD, a diagnosis was not a disqualifying factor: nine participants in the sample had a diagnosis. Full demographic information for this sample can be found in Table 1. Parents/guardians of all participants in the study were provided with informed consent that was approved by the UW Institutional Review Board. Further, all procedures, including recruitment, assent, and behavioral testing, were performed in accordance with the UW Human Subjects Division (HSD).

\begin{tabular}{|l|l|l|}
\hline & \multicolumn{2}{|c|}{ Participants (n=28) } \\
\hline & \multicolumn{1}{|c|}{ Mean } & \multicolumn{1}{c|}{ SD } \\
\hline Age (Y) & 10.18 & 1.37 \\
\hline WJ BRS & 82.62 & 11.3 \\
\hline TOWRE Index & 73.65 & 7.8 \\
\hline WASI FS2 & 101.1 & 14.5 \\
\hline CTOPP PA & 91.77 & 11.1 \\
\hline CTOPP RSN & 85.96 & 12.8 \\
\hline
\end{tabular}


Table 1. Demographic characteristics for Study 1 participants. Means and standard deviations are given for each demographic variable of interest for participants in Study 1. For all variables, other than age, standardized scores are provided.

\section{App Design}

Sound It Out, designed in collaboration with the Advanced Reading Technologies Team at Microsoft, is a web-based application that provides visual annotations to aid in decoding of text. When a reader is viewing a text sample in the Immersive Reader tool - in Microsoft Word or OneNote - Sound It Out is provided as an option to turn on/off at the level of the entire sample or an individual word. Selecting Sound it Out will color each of the voiced vowels blue in the text with corresponding phonemic image cues placed below each vowel. Each image cue is a highly recognizable image whose name contains the associated 'target sound' for the vowel directly above the image (an example is provided in Fig 1). Clicking on the image cues will also provide the reader with an auditory cue for the symbol including the name of the image and the associated target vowel sound. For example, in the word 'sound', the 'ou' would appear in blue font with the symbol of a house below. The house cues the child that the 'ou' in 'sound' has the same vowel sound as /av/ in word 'house'. If a child clicks on the house, the web-app will announce, "house, ou". A more detailed description of the app used can be found in our previous work (Donnelly et al. 2020). 


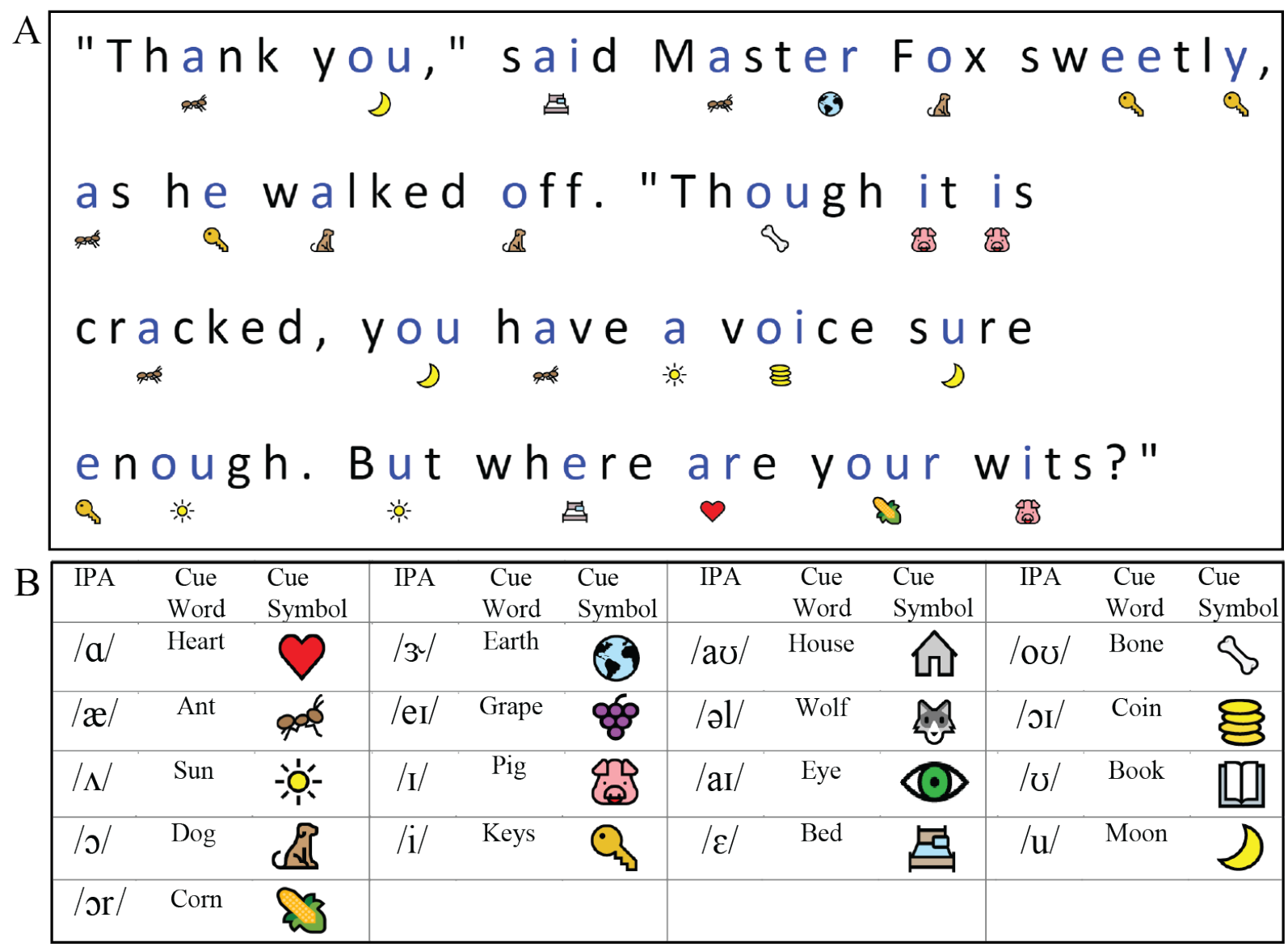

Fig 1. Example of the Sound it Out annotation with legend. Panel ( $A$ ) shows a sample of an Aesop's fable passage with the Sound it Out symbolic vowel annotations. Panel (B) provides a legend of the image cues used, their corresponding names and target vowel sounds.

\section{Study Design}

Using a single-session, cross-over design, this study aimed to build off previous work to determine if a similar cue benefit can be observed immediately, without a period of exposure and practice. In this study, participants were randomly assigned to one of four sets of stimuli presentations with and without the cue. Test stimuli were counterbalanced in presentation order as well as cue condition (normal or cued). Prior to testing, all participants completed a training protocol that was identical to the protocol in the previous work. The protocol involved demonstration of proficiency in identifying the image names, associated target vowel sounds, 
and accessing the voice cue within the app. A more detailed description of the training protocol can be found in the previous work (Donnelly et al. 2020).

\section{Measures}

The following measures were collected during the study: real word decoding, pseudo word decoding, passage reading accuracy, and passage reading rate. In this single session, reading performance was compared across word lists and passages with the cue turned on and off (within subjects, repeated measures design). These measures were collected using identical stimuli to our previous work. Real and pseudo word decoding accuracy were measured using lab-created lists: four, unique lists of 30 real and 30 pseudo words were administered and were developed using the orthographic word form database MCWord (Medler and Binder 2005). Real words, with high frequency in the English database, were selected with five instances each of three-letter to eightletter words. Pseudo words were chosen based on high bigram frequency with an identical progression of three to eight-letter words. All lists were unique, rated as similarly difficult and were administered in a counterbalanced order and cue condition during the study. Further information about validity and reliability can be found in (Donnelly et al. 2020).

Passage reading accuracy and rate were measured using grade-level passages from the Dynamic Indicators of Basic Early Literacy Skills (DIBELS) 6th Edition database. With permission from the University of Oregon Center on Teaching and Learning, two third grade passages were administered to determine if the phonemic cue would assist readers in connected-text reading. Identical to the prior study, the passages were read to completion and scored for accuracy (number of words correct) and rate (correct words per second) in oral reading. Each passage was read once in a counterbalanced order of presentation and cue condition. All measures were administered by a research assistant in the Brain Development \& Education Lab and audio recorded for accurate scoring and coding.

\section{Statistics}

Data were analyzed using linear mixed effects (LME) modelling from the MATLAB Statistics and Machine Learning Toolbox (The MathWorks 2017). Performance on each outcome measure (real word decoding, pseudo word decoding, passage reading accuracy, and passage reading rate) 
were fit with an LME model with a fixed effect for cue condition (cued/uncued). Each model also included two random effects: (1) individual subject and (2) stimulus order group. Based on model comparisons using AIC/BIC fit statistics, an additional random effect of word list was added to the real and pseudoword reading models. In line with our previous work, an adjusted alpha of 0.0125 was used for significance thresholds.

\section{Results: Study 1}

\section{Struggling readers do not benefit from a phonemic cue without practice}

Using grade level passages and lab-created word and pseudoword lists with versus without the Sound it Out image cues, we measured four facets of reading performance: (1) real word decoding, (2) pseudo word decoding, (3) passage reading accuracy, and (4) passage reading rate. Fig 2 shows performance across each of these measures with violin plots of the distributions in each condition and line plots depicting within-subject performance across conditions. 
A

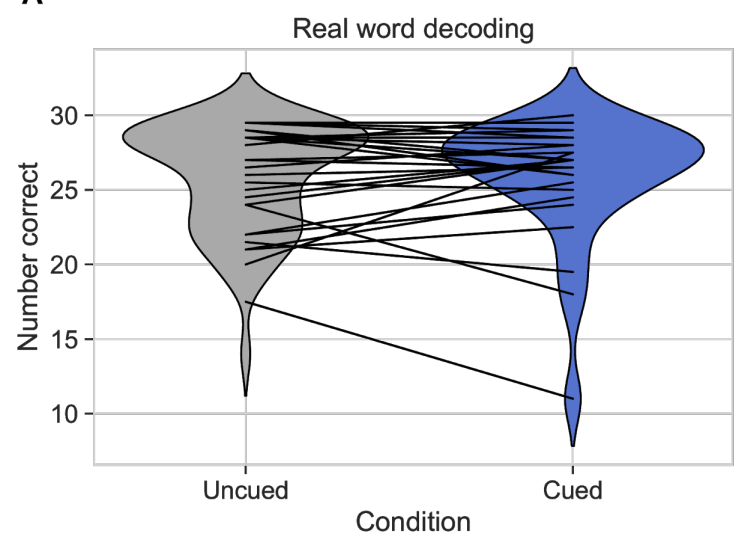

C

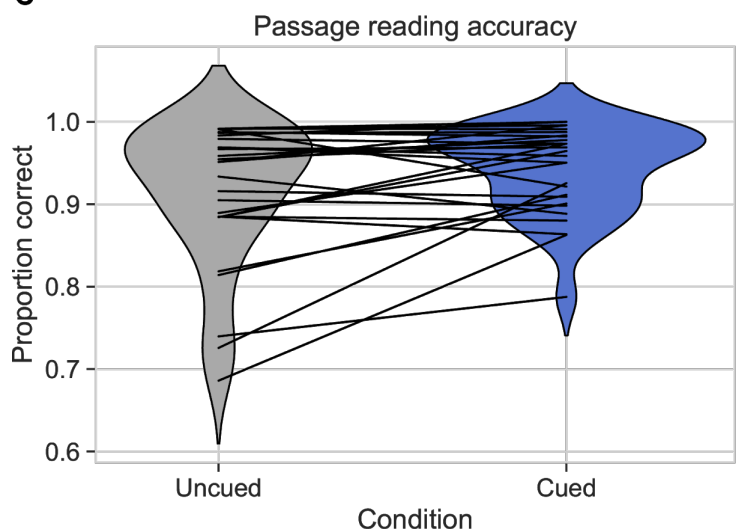

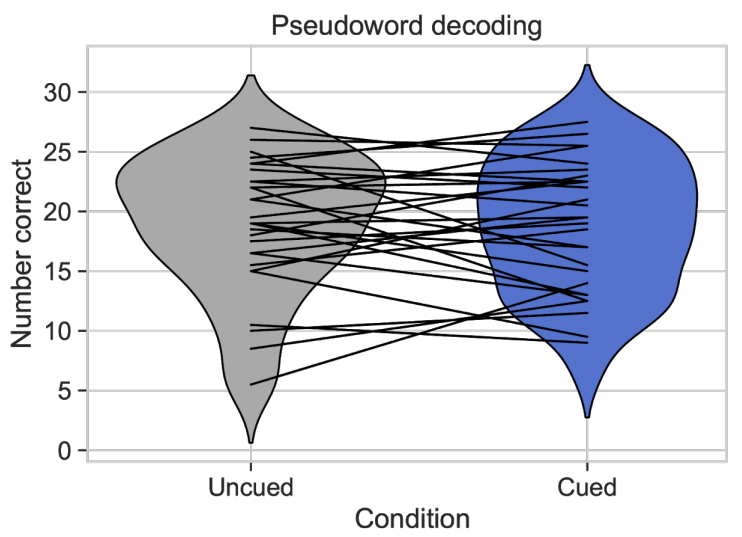

D

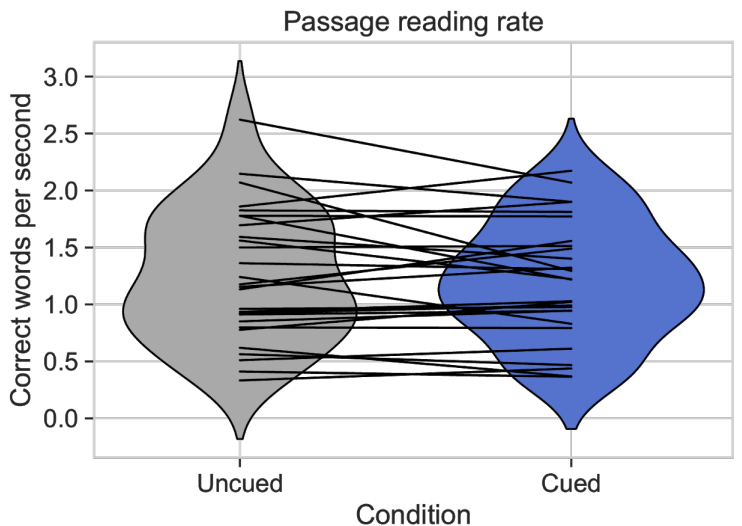

Fig 2. Within-subject performance with and without the cue. Violin density plots show distributions of performance on uncued (gray) and cued (blue) conditions with lines showing individual comparisons across conditions. Plots are shown for real word decoding, pseudoword decoding, passage reading accuracy, and passage reading rate.

Across all outcome measures, we found no significant effect of condition, meaning that performance was equivalent irrespective of whether the cue was turned on or off (real word decoding: $\beta=0.22, \mathrm{t}(108)=0.59, \mathrm{p}=0.557$; passage reading accuracy: $\beta=0.03, \mathrm{t}(52)=2.48, \mathrm{p}=$ 0.016; pseudoword decoding: $\beta=-0.11, \mathrm{t}(110)=-0.17, \mathrm{p}=0.865$; passage reading rate: $\beta=-0.05$, $t(52)=-0.91, p=0.367$. (See Supplementary Table 1 for full model output for each outcome measure). The effect for passage reading accuracy was near-significant, but did not meet our fourcomparison $\alpha$ correction of 0.0125 . Thus, we conclude that a period of practice is necessary for participants to leverage the information in the phonemic cue to improve their reading. 


\section{Discussion: Study 1}

Study 1, which utilized a single-session, crossover design, sought to determine if the app should be considered an adaptive affordance with spontaneous effect or as a supplemental intervention/learning tool requiring a period of exposure or practice. Contrary to our hypothesis, there were no significant differences between performance in the cued and uncued conditions indicating that the cue does not provide immediate benefit to reading performance. Even though children were able to remember the vowel that the cue represented, they did not use the cue to derive a benefit in sounding out complex words.

The results of this study are in line with other findings of the important role of iterative practice in educational technologies for literacy (Messer and Nash 2018; Ronimus and Lyytinen 2015; Grant et al. 2012; Taylor et al. 2020). Albeit intuitive, these findings demonstrate that a period of exposure is necessary for early readers to gain familiarity with the image cues and utilize them in an assessment context. This is supported, in part, by the suggestive benefit observed for passage reading accuracy. During passage reading, a child is additionally motivated by a desire to understand what they are reading, which may provide the necessary encouragement to incorporate even a novel strategy. This is juxtaposed with the non-significant results for measures of single word decoding, where the motivation may be just to get through the list as quickly as possible. As supported by related work, technologies such as Sound it Out are more impactful when implemented in a highly engaging, motivating context (Larson 2010; Hutchison, Beschorner, and Schmidt-Crawford 2012; Wolf et al. 2014; Tare, Shell, and Jackson 2020).

Based on these findings, our focus shifted to (a) the duration of and (b) type of practice/exposure which would lead to benefits for measure of decoding and fluency. In a second, follow-up study, we implemented Sound it Out for an extended period (one month) with a dual intervention group. An independent intervention group was trained and asked to practice on their own, and a dyadic reading group was trained and asked to practice only with a caregiver present. These two intervention groups were compared against an independent reading control group. 


\section{Methods: Study 2}

\section{Participants}

Eighty-one participants between 8 and 13 years old were recruited from the same database based on the same characterization criteria used in Study 1 for struggling readers. Due to participant attrition, seventy-six participants completed at least two sessions to be included in the sample. Study groups were evenly represented in terms of participant sex (control = 11 female; independent $=11$ female; dyadic $=11$ female) as well as the other demographic variables collected (see Table 2). Forty-three had a diagnosis of dyslexia ( control =16; independent $=15$; dyadic $=13$ ) and twenty-two had a diagnosis of ADHD (control =9; independent =6; dyadic =7). As with Study 1, all procedures, including remote assessment due to the COVID-19 pandemic, were approved by the UW HSD.

\begin{tabular}{|l|c|c|c|c|c|c|c|c|}
\hline & \multicolumn{2}{|c|}{$\begin{array}{c}\text { Control } \\
(\mathrm{n}=25)\end{array}$} & \multicolumn{2}{c|}{$\begin{array}{c}\text { Independent } \\
(\mathrm{n}=26)\end{array}$} & \multicolumn{2}{c|}{$\begin{array}{c}\text { Dyadic } \\
(\mathrm{n}=25)\end{array}$} & \multicolumn{2}{c|}{$\begin{array}{c}\text { Kruskal-Wallis } \\
\text { Test }\end{array}$} \\
\hline & Mean & SD & Mean & SD & Mean & SD & X $^{2}$ & p \\
\hline Age (Y) & 10.50 & 1.21 & 10.68 & 1.56 & 10.50 & 1.29 & 0.18 & 0.912 \\
\hline WJ BRS & 84.08 & 9.49 & 80.62 & 10.08 & 81.92 & 10.47 & 1.92 & 0.383 \\
\hline TOWRE & 73.44 & 7.77 & 73.77 & 6.48 & 73.80 & 8.35 & 0.15 & 0.927 \\
\hline WASI FS2 & 100.68 & 10.55 & 106.46 & 13.29 & 101.80 & 11.34 & 2.89 & 0.236 \\
\hline CTOPP PA & 91.12 & 9.33 & 92.31 & 12.88 & 87.72 & 11.58 & 2.27 & 0.321 \\
\hline CTOPP RSN & 78.92 & 20.54 & 79.92 & 12.54 & 83.17 & 9.46 & 2.12 & 0.346 \\
\hline
\end{tabular}


Table 2. Demographic characteristics for Study 2 participants. Means and standard deviations are given for each demographic variable of interest for participants in Study 2 for each of the study groups: control, independent readers, and dyadic readers. Chi-square statistics and $p$ values from Kruskal-Wallis tests reveal that there is no significant difference across groups.

\section{App Design}

As described in Study 1/App Design (above), Sound it Out is a web-app that provides a phonicsgrounded, annotational scaffold for decoding vowels in connected-text reading. Study 2 utilizes the same app, but with some minor improvements and modifications. Rather than the manual coding that was performed in previous iterations, the vowel coding is standardized using a textto-speech API developed by Microsoft: the Speech Application Programming Interface (SAPI). Additionally, the voice cues were updated to provide professionally recorded narration with extended vowel sounds (Fernald and Kuhl 1987; Patricia K. Kuhl 2000; P. K. Kuhl et al. 1997).

In Study 1 and previously, there was concern (both participant-reported and researcherobserved) that the image cues were not optimal for the target population: struggling readers. The image cues were chosen as highly recognizable monosyllabic images that would require little instruction, were already used in vowel teaching in classrooms, and focused on word-middle sounds: "bed" for the sound /ع/ and "pig" for the sound/I/. As phonological elision is difficult for dyslexic and struggling readers, especially for word-middle sounds (Snowling 2004), we created and tested an alternative set that optimized for word-initial sounds (an easier type of elision): "elephant" for the sound / $\varepsilon /$ and "igloo" for the sound /I/. (see Supplemental Table 2 for side-byside image set comparison)

The two image cue sets, termed "Pigs \& Suns" and "Igloos \& Umbrellas", were tested in a smallscale validation study with twenty-two typically reading $($ WJ BRS; mean $=105.95$, sd $=14.24$ ) children ages 7 to 15 years old (female $=10$, male $=12$ ). Participants were randomized to either image set and given a brief training to learn the images and their associated vowel sounds. Training utilized flashcards and was complete when each participant demonstrated mastery of each image and its associated target sound. Then the participants were tested using 35 flashcards displaying single words with the vowels replaced by images in their trained image set. For 
example: H $\operatorname{dog}$ N ("Pigs \& Suns" set) or H octopus N ("Igloos \& Umbrellas" set), with the correct response of /han/. Accuracy was measured as the number of correctly pronounced items in the set.

We compared performance using an independent samples t-test and found that (a) participants easily learned both symbol sets and (b) there was no significant difference in performance between the two sets $(\mathrm{t}(20)=-0.25, \mathrm{p}=0.806)$ (see Supplemental Fig 1). Although these results do not discount issues of individual preference, these findings demonstrate that there is no compelling reason to change the cue set for the current study. The Pigs \& Suns set was implemented once again in Study 2.

\section{Study Design}

In a randomized, repeated-measures design, 76 participants were randomly assigned to one of three participant groups: a single control group and two intervention groups - independent and dyadic. Participants were randomly assigned based on time of consent and sibling participants were assigned to the same group for protocol adherence. All participants were asked to complete three in-person or virtual testing sessions and two, two-week practice periods with the aid of a touch-screen device larger than a smartphone. To reduce issues of access, participants were given the option of a lab-provided Kindle Fire HD 8 for use during the course of the study.

During session one, all participants completed baseline testing of all measures using the uncued condition (test without Sound it Out) (see Measures). The two intervention groups then underwent a short training program that introduced them to the image cues, the target vowel sounds and voice cues (see (Donnelly et al. 2020) for a more detailed description of the paradigm). For the dyadic group, a parent/caregiver was asked to participate actively in the training and demonstrate similar proficiency in using the web-app. After training, both intervention groups were instructed to complete at least five passages per week with Sound it Out enabled for the next two weeks prior to session two. Those in the dyadic reading group were instructed to read with a parent/caregiver while independent readers were asked to read alone. Practice was tracked using brief comprehension quizzes (see Measures). In session two, intervention participants completed testing in all outcome measures, but using the cued condition (with Sound it Out). 
Participants then completed an abbreviated 'refresher' training program (with a caregiver for the dyadic group) and asked to adhere to the same practice regimen for the final two-week period. In their final session, participants once again completed all outcome measures in the cued condition before completing a researcher-administered questionnaire.

Control participants completed identical, two-week practice periods and testing sessions, but using only the uncued condition (normal digital text). Training, moreover, was limited to a tour of the app and instructions for completion of the comprehension quizzes. Control participants were asked to read independently.

\section{Measures}

One primary and four secondary outcome measures were collected at all three time points: decoding accuracy, real word decoding, pseudo word decoding, passage reading accuracy and passage reading rate. Real and pseudoword decoding were measured using lab-created word lists generated using the orthographic word form database MCWord (Medler and Binder 2005). Each of the six lists consisted of 30 unique real or pseudo words, with two lists administered at each session. Real words lists contained five items each of three- to eight-letter words, selected for high English-language occurrence. Pseudoword lists were similarly structured, but were generated based on English bigram frequency identically scaled from three- to eight-letter words. All lists consisted of unique words/pseudowords and were administered in a counterbalanced order across participants. (see Supplemental Tables 3 and 4 for detailed frequency statistics). As with the previous study (Donnelly et al. 2020), the lists were calibrated for difficulty and were phonetically coded manually by the first author based on common pronunciation in the regional dialect. As there are multiple pronunciations for many of the words, accuracy was scored using any acceptable pronunciation of the word items. For pseudowords, accuracy was scored using most common pronunciations of any given bigram, as defined prior to the start of the study. List reliability was calculated using the correlation between the first and second list administered at each session. Results show high reliability in performance for both real word $(r=0.89, p<0.001)$ and pseudoword $(\mathrm{r}=0.89, \mathrm{p}<0.001)$ lists. Decoding accuracy (the primary outcome measure) was calculated as a composite of real- and pseudo-word reading accuracy. Real and pseudoword decoding were pre-defined as secondary outcome measures. 
Passage reading accuracy and rate were measured using levelled test passages from the Dynamic Indicators of Basic Early Literacy Skills (DIBELS) 8th Edition library. These passages consisted of six, fourth-grade level passages from the Oral Reading Fluency subtest and were used with permission from the University of Oregon Center on Teaching \& Learning. Designed to be administered for progress monitoring in the classroom, these passages are commonly used in both research and practice. For testing, passages were viewed within the Immersive Reader tool to both standardize font properties across participant groups and reduce distractions typical of a digital reading environment. For the cued condition, test passages were phonetically-coded by SAPI. At each session, two passages were read twice in a repeated reading design and were audio recorded for accurate scoring and coding. Analyses focused on the accuracy of the first read (number of words pronounced correctly) and the rate of the second read (accurate words per second). With these two measures, we aimed to uncover the effect of the cue independent of the expected consequences of implementing a novel strategy for fluency. First read accuracy and second read rate were pre-defined as secondary outcomes.

For practice, participants were provided with a bank of seventy-five, second- to fifth-grade passages for daily reading. The passages were accessed (with permission) from both the DIBELS 6th Edition library and ReadWorks.org. Passages were chosen for diverse interests/topics and, for the intervention groups, coded using the Microsoft speech API. For each passage, a short, 3question comprehension quiz followed to log practice adherence. Comprehension questions were created by a Master's level teacher certified to work with struggling readers and were grade-level matched to the specific passage. Practice was measured as the number of quizzes completed.

\section{Statistics}

Using the results and effect sizes from previous work (including Study 1), we pre-defined our analysis to test (A) the difference between the combined intervention groups and the control (intervention effect) and (B) the difference between the two independent intervention groups (group effect) using one primary (decoding accuracy) and four secondary outcome measure (real word decoding, pseudoword decoding, passage reading accuracy, and second read rate). An a priori power analysis was conducted using $\mathrm{G}^{*}$ Power3 (Faul et al. 2007). A medium-to-large effect 
size of .80 standard deviation (SD) units was hypothesized for both comparisons A and B. In this case, a total sample size of 75 participants across the three groups (control $=25$, independent $=25$, dyadic $=25$ ) would provide approximately $90 \%$ power for comparison A and $80 \%$ power for comparison B using a two-sided alpha $=.05$. To accommodate possible dropout over the course of the study, 81 participants were recruited to ensure that a sufficient number would complete all study sessions.

Thus, analyses examined the impact of Sound it Out on the primary and secondary outcome measures at two levels: the intervention effect and the group effect. For both levels, we implemented LME modelling to explore both within- and between-subject effects. Models were fit with fixed-effects of (1) time (session as a categorical variable), (2) group (intervention/control or independent/dyadic as a categorical variable), and (3) group by time interaction. All models contained random effects for time and participant to account for individual variation in baseline and slope. For decoding measures, an additional random effect of specific list was added based on model fit comparison analysis using AIC/BIC statistics.

Post-hoc analyses were performed to explore the impact of four moderator variables: age, WJ BRS, TOWRE Index, and CTOPP phonological awareness. These analyses utilized a LME model with fixed effects of (1) moderator and (2) time, with identical random effects structures to the primary analyses.

\section{Results: Study 2}

\section{With prolonged exposure, benefits increase and extend to connected-text reading}

We first compared the combined intervention groups to the control group (Comparison A, see Methods) to determine if we could, first, replicate previous findings of an effect on isolated, pseudoword decoding and, second, whether this reading benefit would extend to higher-order skills with a doubling to the practice period.

The primary outcome measure, Decoding accuracy, was calculated as a combination of performance on real word and pseudoword decoding measures, which were individually 
analyzed as secondary outcome measures. Words were presented in a vertical list and administered free of time constraints. Secondary outcome measures of passage reading accuracy and rate were assessed using digitally-presented passages. Fig 3 depicts group level distributions and individual changes at the start and end of the intervention period.
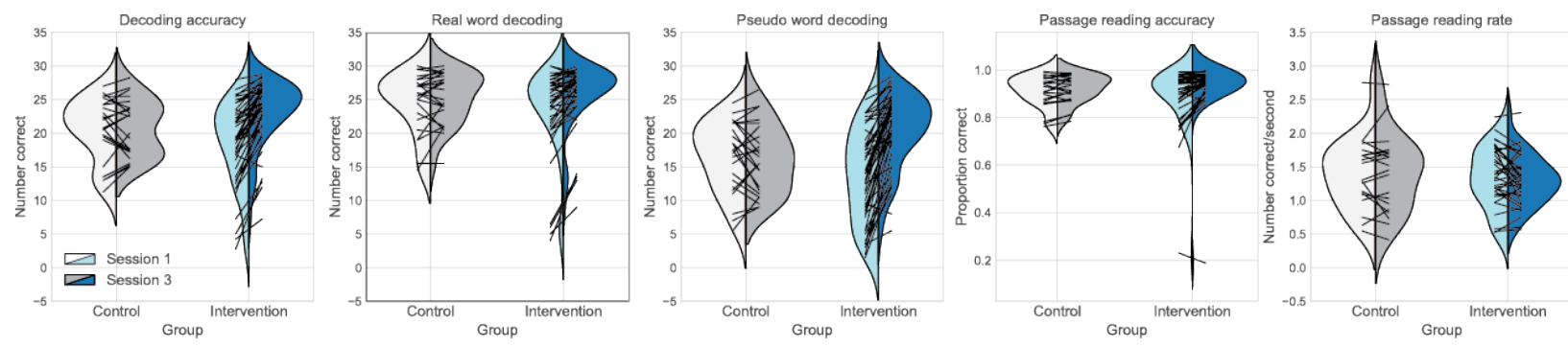

Fig 3. Within-subject pre-post intervention performance. Violin density plots show distributions of performance for the control (gray) and the combined intervention (blue) conditions. Individual line plots depict participant-level performance at sessions 1 and 3. Plots are shown for the decoding accuracy composite, real word decoding, pseudoword decoding, passage reading accuracy, and passage reading rate.

For comparison A, the primary outcome measures of decoding accuracy showed a highly significant group by time interaction at both midpoint $\left(\beta=2.58, \mathrm{t}(895)=4.26, \mathrm{p}=2.28^{*} 10^{-5}\right)$ and post-test $\left(\beta=4.28, \mathrm{t}(895)=5.73, \mathrm{p}=1.34^{*} 10^{-8}\right)$. The amount of growth was roughly equivalent between each timepoint. These results indicate that growth in the combined intervention groups was significantly different than the control group, and that the observed growth follows a roughly linear, dose-response trajectory (see Fig 4). 

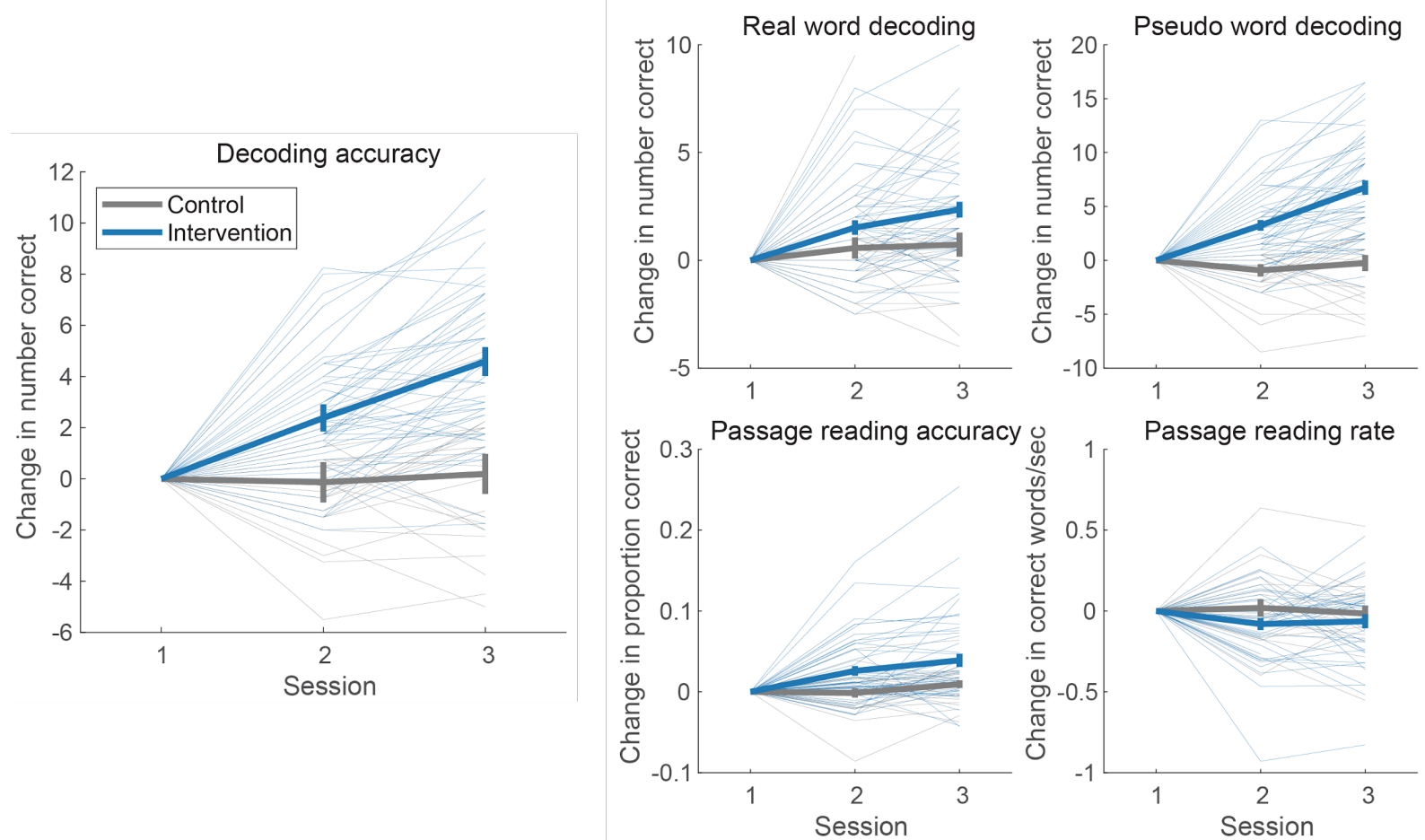

Fig 4. Rate of change plots for intervention effect comparison. For each outcome measure line plots depict change at the group-level from the LME model for the combined intervention group (blue) and the control group (gray). Although individual intercepts are removed for visualization, model fits are calculated with the full fixed and random effects structure defined in the Methods. Individual slopes are plotted to demonstrate variability between-subjects. Error bars represent +/- 1 SEM.

As decoding accuracy was a composite of real and pseudoword decoding accuracy, we examined the component measures as secondary outcome measures. For pseudo word decoding, the group by time effect was significant at both time points (midpoint: $\beta=4.21, \mathrm{t}(444)=5.15, \mathrm{p}=3.85^{*} 10^{-7}$, post-test: $\left.\beta=6.96, \mathrm{t}(444)=6.39, \mathrm{p}=4.21^{*} 10^{-10}\right)$. These findings replicate previous findings and demonstrate additional benefit of the cue with additional practice/exposure. For real word decoding, the group by time effect was not significant at midpoint $(\beta=0.95, \mathrm{t}(445)=1.62, \mathrm{p}=$ $0.105)$ but significant at post-test $(\beta=1.64, \mathrm{t}(445)=2.57, \mathrm{p}=0.011)$. These results replicate previous findings (i.e the lack of effect at session 2 (Donnelly et al. 2020) and extend these previous results to provide evidence for benefits to real word reading skills with prolonged exposure. 
To examine the effect of the cue on connected-text reading for comparison A, we examined two secondary outcome measures: passage reading accuracy and rate. For passage reading rate, the group by time interaction was not significant at either time point (midpoint: $\beta=-0.10, t(176)=$ 1.57, $\mathrm{p}=0.117$; post-test: $\beta=-0.07, \mathrm{t}(176)=-1.01, \mathrm{p}=0.315)$. For passage reading accuracy, the group by time interaction was significant at both midpoint $(\beta=0.03, \mathrm{t}(208)=2.86, \mathrm{p}=0.005)$ and post-test $(\beta=0.03, t(208)=2.50, p=0.013)$. (See Supplementary Table 5 for full model output for each outcome measure). These results demonstrate that with prolonged practice with the Sound it Out cue, benefits are observed beyond single word decoding, generalizing to measures of reading fluency.

\section{A significant advantage of supervised reading for passage reading accuracy}

Our second comparison (B) focused on the two intervention groups to determine if there was an effect of type of practice (independent versus dyadic reading) on Sound it Out cue benefit. In this analysis, we sought to disambiguate the role of the cue as a scaffold for independent reading or an aid in empowering a shared reading experience with a parent or caregiver. Fig 4 shows performance across the primary and secondary measures for those in the two intervention groups. 

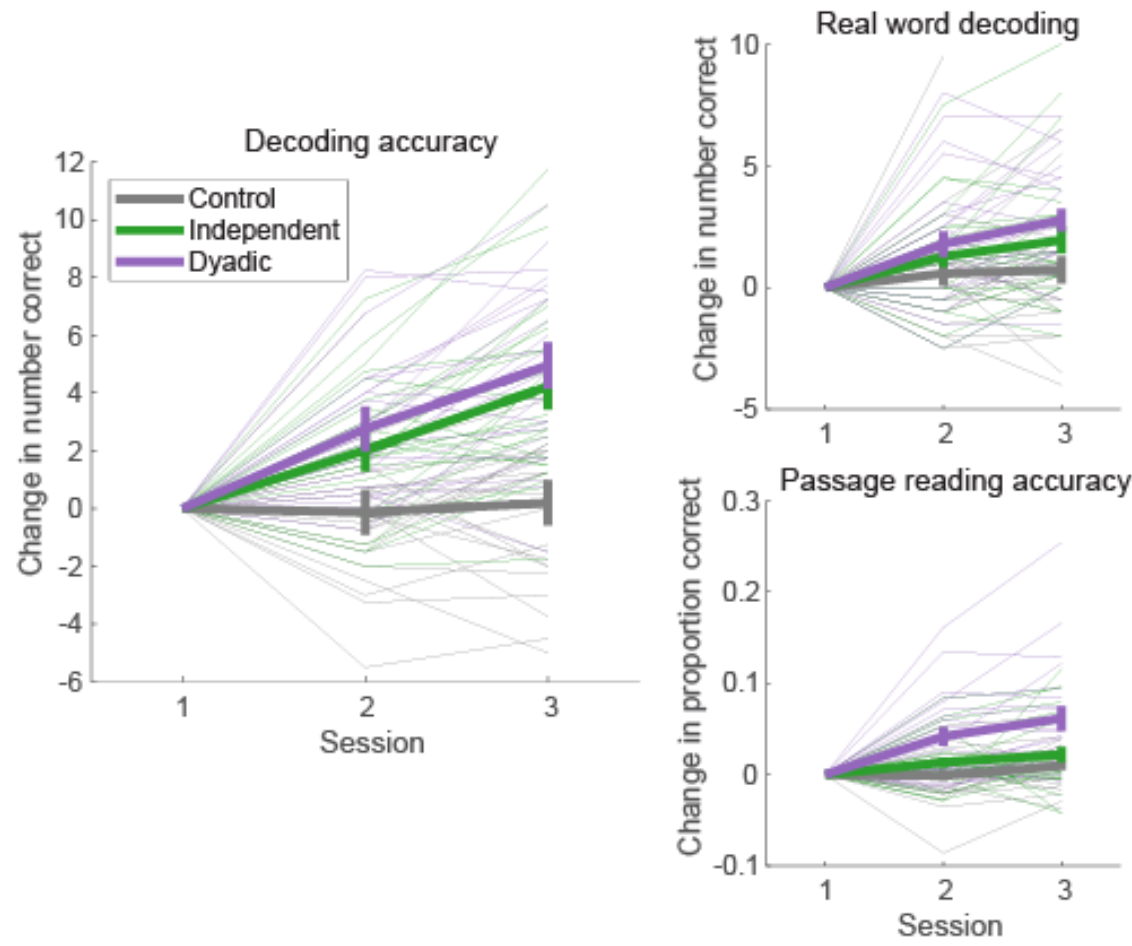
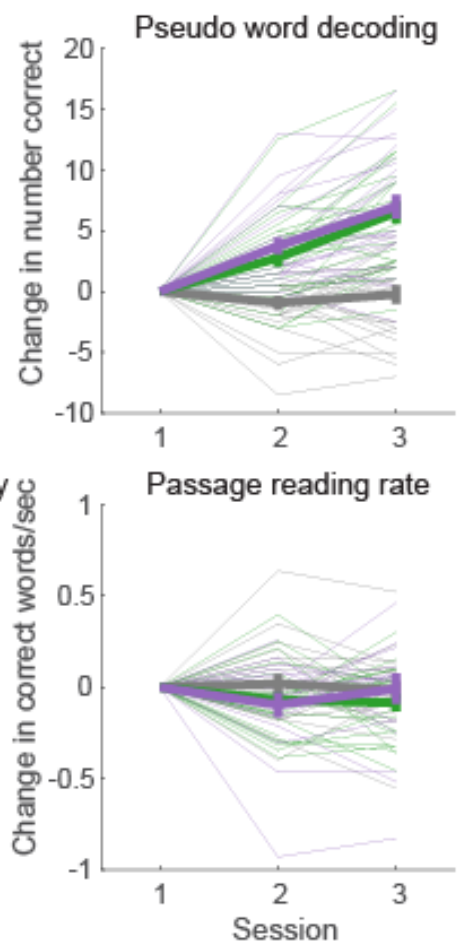

Fig 5. Rate of change plots for comparison between dyadic and independent intervention groups. For each outcome measure line plots depict rate of change at the group-level from the LME model for the dyadic reading group (purple), the independent reading group (green), and control (gray). Although individual intercepts are removed for visualization, model fits are calculated with the full fixed and random effects structure defined in the Methods. Individual slopes are plotted to demonstrate variability between-subjects. Error bars represent +/- 1 SEM.

For comparison B of the decoding accuracy primary outcome measure, the group (Dyadic vs. Independent) by time effect was not significant at midpoint $(\beta=0.74, \mathrm{t}(603)=1.05, \mathrm{p}=0.296)$ or post-test $(\beta=0.66, t(603)=0.75, p=0.455)$. This suggests that both groups benefited equally and there is no significant difference between the type of practice for measures of single word decoding. This is reflected in both component measures for pseudo word decoding (midpoint: $\beta$ $=0.97, \mathrm{t}(298)=0.98, \mathrm{p}=0.327$; post-test: $\beta=0.49, \mathrm{t}(298)=0.37, \mathrm{p}=0.713)$ and real word decoding (midpoint: $\beta=0.51, \mathrm{t}(299)=0.76, \mathrm{p}=0.445$; post-test: $\beta=0.83, \mathrm{t}(299)=1.16, \mathrm{p}=0.248$ ). 
As with the previous comparison, we examined the effect on two measures of connected-text reading: passage reading accuracy and rate. For passage reading rate, the group by time effect was not significant at either time points (midpoint: $\beta=-0.03, \mathrm{t}(116)=-0.43, \mathrm{p}=0.665$; post-test: $\beta$ $=0.05, \mathrm{t}(116)=0.55, \mathrm{p}=0.58)$; however, for passage reading accuracy, the group by time effect was significant at both midpoint $(\beta=0.03, \mathrm{t}(134)=2.41, \mathrm{p}=0.017)$ and post-test $(\beta=0.04, \mathrm{t}(134)=2.37$, $p=0.019$ ). (See Supplementary Table 6 for full model output for each outcome measure). These results demonstrate that there is a potential, enhanced benefit to supervised, shared reading for connected-text reading accuracy.

\section{Cue may be particularly impactful for younger readers with greater struggles}

In an exploratory analysis, we examined the role of five moderators (WJ BRS, TOWRE Index, CTOPP Phonological Awareness, CTOPP Rapid Naming, and chronological age) in predicting the benefit of the cue on our primary and secondary outcome measures. The goal of these analyses were to investigate potential subgroup differences that influence the impact of Sound it Out. For example, because the cue relies on phonological awareness skills (i.e. elision) to isolate the target vowel sounds from the symbol names, the cue may be more well-suited for those with higher scores on tests of phonological elision (CTOPP PA).

For these analyses, an LME model was fit to data for the combined intervention groups with fixed effects of (1) time (session as a categorical variable), (2) moderator, and (3) moderator by time interaction. Identical random effects structures to the main analyses were used. Using this method we examined whether the cue response was affected by performance along the moderator continuua.

For decoding accuracy, suggestive moderator by time interactions were found for two variables: TOWRE Index and chronological age. Results indicate that the cue may benefit those with lower TOWRE Index scores (midpoint: $\beta=-0.078, \mathrm{t}(603)=-1.58, \mathrm{p}=0.114$; post-test: $\beta=-0.15, \mathrm{t}(603)=-$ 2.64, $\mathrm{p}=0.008$ ) as well as younger users (midpoint: $\beta=-0.02, \mathrm{t}(603)=-0.79, \mathrm{p}=0.406$; endpoint $=$ $\beta=-0.06, t(603)=-2.41, p=0.016)$. No effects were observed for CTOPP PA, CTOPP Rapid Naming or WJ BRS. 
For the two component measures of decoding accuracy, results indicate that the observed associations are specific to real word decoding performance. For real word decoding, suggestive interaction effects were found for TOWRE Index (midpoint: $\beta=-0.13, t(299)=-3.13, p=0.002$; post-test: $\beta=-0.17, \mathrm{t}(299)=-3.88, \mathrm{p}=0.0001$ ), WJ BRS (midpoint: $\beta=-0.07, \mathrm{t}(299)=-2.07, \mathrm{p}=0.039$; post-test: $\beta=-0.04, \mathrm{t}(299)=-1.25, \mathrm{p}=0.211$, and chronological age (midpoint: $\beta=-0.05, \mathrm{t}(299)=$ 2.72, $\mathrm{p}=0.007$; post-test: $\left.\beta=-0.07, \mathrm{t}(299)=-4.00, \mathrm{p}=7.89^{*} 10^{-5}\right)$. These results indicate that the Sound it Out cue may be more beneficial for both more impaired and younger readers. No interaction effects were found for pseudo word decoding.

For passage reading accuracy, there was a small interaction effect for chronological age (midpoint: $\beta=9.8^{*} 10^{-4}, \mathrm{t}(134)=-2.82, \mathrm{p}=0.006$; post-test: $\beta=1.2^{*} 10^{-3}, \mathrm{t}(134)=-2.56, \mathrm{p}=0.012$ ) but no suggestive associations across reading-related moderators, compounding the results with decoding measures to suggest that the cue may have greater impact for younger readers. No significant associations were found for passage reading rate performance.

\section{Discussion: Study 2}

Building on the knowledge gained from Study 1, we endeavored to find out if extended exposure and prescriptive practice could produce proportional gains that generalize to aspects of fluent reading skill. Using an RCT methodology, we asked: (1) Will prolonged exposure translate to added and generalized benefits to reading skill? and (2) Can motivated practice with a parent/caregiver impact the benefit of the phonemic image cue? Participants were randomly assigned to two intervention groups - independent and dyadic readers - and a matched control to examine two comparisons of interest: (A) the intervention comparison - combined intervention groups versus control and (B) the group comparison - independent readers versus dyadic readers.

Results from comparison A demonstrate significant group by time interaction effects for the primary outcome measure, decoding accuracy, as well as the secondary measures of real word decoding, pseudo word decoding, and passage reading accuracy. These results replicate previous findings, and demonstrate that observed benefits compound with prolonged usage and extend to areas of reading fluency (connected text reading accuracy). From comparison B, results show 
that although there was no significant group by time interaction for measures of decoding, there was a significant advantage for the dyadic reading group for passage reading accuracy. These results confirm our hypotheses, but open additional questions about individual variability. To examine these individual differences, we conducted an exploratory analysis on various moderator variables. Results indicate negative moderator by time interactions for real word reading and passage reading accuracy and suggest that, with future research, the cue may be ideally suited to younger readers and those with the most substantial struggles.

\section{General Discussion:}

Due in part to troubling national literacy rates and the prevalence of reading-related disabilities, there has been high demand for educational technologies to support emerging readers outside the classroom (Guernsey and Levine 2015). According to recent reports, literacy rates for American youth are declining. Since the previous iteration in 2017, the 2019 Reading Report Card reports that the percentage of U.S. fourth graders performing at or above proficiency in reading has decreased from $37 \%$ to $35 \%$. This pattern is mirrored for eighth graders which observed a decrease from $36 \%$ to $34 \%$, and is significantly pronounced for students in ethnic and racial minority populations (National Assessment of Educational Progress 2019). Moreover, it is estimated that roughly $15 \%$ of the population has developmental dyslexia (Lyon, Shaywitz, and Shaywitz 2003; Wolf 2007), the most prevalent and studied of the learning disabilities (Fletcher et al. 2018). These statistics paint a troubling landscape for youth in the U.S. as literacy rates in these foundational years are highly predictive of long term educational outcomes (The Annie E. Casey Foundation 2013; Rabiner et al. 2010; Maughan 1995) and overall health and longevity (Gilbert et al. 2018).

To address these poor literacy achievement rates, and regardless of etiology, many educators and caregivers have turned to digital solutions. The utility and accessibility of technology make it markedly appealing to reading education, but existing research is insufficient to inform those interested in how to utilize digital tools effectively. The goal of the present research was to address this need and contribute to the burgeoning literature on educational technologies for struggling readers with one such digital tool: Sound it Out. 
Using a pair of studies, we applied controlled study environments to elucidate not only the legitimacy of the cue for improving reading skill, but also contextualize the manner of use that allows for that improvement. Together, the results from studies 1 and 2 support the implementation of Sound it Out as a meaningful scaffold for both independent and shared reading environments. With a brief training and motivated exposure, children who read on their own, or with an adult, demonstrated measurable gains in decoding accuracy. Additionally, those who read with an adult made significant gains in fluency, particularly for younger readers. These results support consistent research in literacy education of the added value that an adult tutor or caregiver brings to fore, especially for emerging readers (Ronimus and Lyytinen 2015; Cheung and Slavin 2013; Lynch et al. 2006; Hannon and James 1990; Tichnor-Wagner et al. 2016; Auerbach 1989; Kraft and Monti-Nussbaum 2017). Recent studies have shown that even a non-caregiver adult allows for a 'tutor/child/computer triangle' providing both pedagogical and socioemotional motivation (McTigue et al. 2020). Because of the role that caregiver encouragement played in our study, results also suggest that Sound it Out may also be ideally suited for peer-supported learning. Growing evidence has clarified the proximal advantage of peer learning strategies, both inside and outside the classroom (Drummond, Chinen, and Duncan 2011; Fuchs and Fuchs 2005; Tare, Shell, and Jackson 2020). Future research should explore the potential role of peer learning with Sound it Out.

Even though these findings are encouraging, there are important limitations to consider. First, in Study 2 we did not test the intervention groups on their performance without the cue, and control participants were never exposed to the cue. As a result, we are unable to discuss the ability of the cue to generalize to uncued reading. Based on results from a 10 month RCT of a related technology (Messer and Nash 2018), we have reason to expect that, over time, the cue would help scaffold phonics knowledge and benefit reading skills more generally. But that still remains to be tested. Second, we are unable to determine whether a period of caregiver-included practice without the cue would relate to comparable improvements in decoding and passage reading fluency. Third, although the groups were given clear instructions on how to practice (independently vs. dyadically), there was no ability to enforce adherence. We did, however, collect comprehensive parent-reported usage statistics which demonstrate overall coherence (see Supplemental Fig 2). Future research should study effects over the course of an academic year 
to explore generalizability and leverage detailed app usage data to add granularity to the impacts of the type of exposure. Finally, due to the variability in our sample, it will be necessary to conduct future studies with larger sample sizes and smaller age ranges to reduce the possibility of ceiling effects and regression to the mean in the current studies.

Considering these positive effects, the true impact of Sound it Out will depend on its ability to supplement what the reader learns in the classroom. Consistent across the literature on educational technologies is the importance of programs to integrate with and supplement existing curricula (Lee et al. 2013; Taylor et al. 2020; Tare, Shell, and Jackson 2020; Ok and Rao 2019; Christ, Arya, and Liu 2018). Namely, existing research has shown that although the degree of benefit is linked to the amount of exposure with a caregiver, the degree of utilization is more significantly linked to the amount of exposure at school (Ronimus and Lyytinen 2015). As our findings suggest that the amount of utilization is critical (the more a child was exposed to the tool, the more they improved across outcome measures), future research that involves schools is needed to reveal the true potential of Sound it Out.

During development of Sound it Out, persistent challenges were the consistency of the speech API-generated phoneme with participants' spoken dialects and the choice of image cues. Together with Microsoft, our goal was to implement a code that aligned with the International Phonetic Alphabet (IPA), but also matched most common pronunciations in Pacific Northwest regional dialect (where the study was conducted). The most consistent feedback from participants was a perceived mismatch between what they expected to see and the symbol that was supplied. This sets a challenge for future research - to modify cues to match individual dialects (Hattan and Lupo 2020; Noguerón-Liu 2020; Hoffman, Hikida, and Sailors 2020; Willis 2019). As for the image cues, our primary goals were to choose symbols that were easily recognizable and in alignment with commonly used images in curricula. As our studies have shown, the chosen symbols were quantifiably effective, but qualitatively, image favor was more mixed. In post study surveys several participants noted a desire to use alternate image cues either to align with specific instructional materials or as a matter of personal preference.

Fortunately, one of the many affordances of digital tools is their ability to adapt to individual variation. Just as word processors provide a selection of fonts for their users, technological tools 
like Sound it Out are inherently modular to adapt to user preference. In the future, not only will this allow schools and families to select the most meaningful images for their beginning readers, but it will also allow for the tool to adapt to dialectal and regional variation. For speakers of a minority dialect (such as African American English (AAE)), the erasure of minority dialects in mainstream education has been shown to be detrimental to reading development (Brown et al. 2015). With the ability of a tool like Sound it Out to adapt a child's home and school environment, educational technologies can help establish 'cultural synchronization' by expanding access to culturally-relevant text (Scott and Marcus 2014; Washington 2001; Phillips Galloway, McClain, and Uccelli 2020). This is a promising direction for Sound it Out to provide a culturally-relevant affordance that can broaden access to multicultural knowledge (Hattan and Lupo 2020).

To conclude, this pair of studies demonstrates that Sound it Out, a phonemic image cue annotation for vowels, can effectively support emerging readers more accurately decode complex words and passages. This tool represents a simple adaptation that is fundamentally modular, and grounded in principles of phonics, to provide a meaningful and adaptable cue to scaffold sound-letter correspondence. In the world of educational technologies, Sound it Out unites pedagogical practice and developer expertise to create an impactful, accessible aid for emerging readers. When in-person learning is not possible, and extending into the future when it is, this combination empowers families to take an active, participatory role in their child's learning. 


\section{References:}

Abrami, Philip C., Larysa Lysenko, and Eugene Borokhovski. 2020. “The Effects of ABRACADABRA on Reading Outcomes: An Updated Meta-analysis and Landscape Review of Applied Field Research." Journal of Computer Assisted Learning, February, jcal.12417.

Abu-Rabia, Salim. 1999. "The Effect of Arabic Vowels on the Reading Comprehension of Second- and Sixth-Grade Native Arab Children." Journal of Psycholinguistic Research 28 (1): 93-101.

- - - 2001. “The Role of Vowels in Reading Semitic Scripts: Data from Arabic and Hebrew." Reading and Writing 14 (1-2): 39-59.

Atkinson, Richard C., and Duncan N. Hansen. 1966. “Computer-Assisted Instruction in Initial Reading: The Stanford Project." Reading Research Quarterly 2 (1): 5.

Auerbach, Elsa Roberts. 1989. "Toward a Social-Contextual Approach to Family Literacy." Harvard Educational Review 59 (2): 165-82.

Barker, Theodore Allen, and Joseph K. Torgesen. 1995. “An Evaluation of Computer-Assisted Instruction in Phonological Awareness with below Average Readers." Journal of Educational Computing Research 13 (1): 89-103.

Benton, Laura, Asimina Vasalou, Kay Berkling, Wolmet Barendregt, and Manolis Mavrikis. 2018. "A Critical Examination of Feedback in Early Reading Games." Proceedings of the 2018 CHI Conference on Human Factors in Computing Systems - CHI '18, 1-12.

Benton, Laura, Asimina Vasalou, Rilla Khaled, Hilary Johnson, and Daniel Gooch. 2014. "Diversity for Design: A Framework for Involving Neurodiverse Children in the Technology Design Process." Proceedings of Conference on Human Factors in Computing Systems, 3747-56.

Blok, H., R. Oostdam, M. E. Otter, and M. Overmaat. 2002. “Computer-Assisted Instruction in Support of Beginning Reading Instruction: A Review." Review of Educational Research 72 (1): 101-30.

Brown, Megan C., Daragh E. Sibley, Julie A. Washington, Timothy T. Rogers, Jan R. Edwards, Maryellen C. MacDonald, and Mark S. Seidenberg. 2015. "Impact of Dialect Use on a Basic Component of Learning to Read." Frontiers in Psychology 6 (MAR): 1-17.

Campuzano, Larissa, Mark Dynarski, Roberto Agodini, and Kristina Rall. 2009. "Effectiveness of Reading and Mathematics Software Products: Findings From Two Student Cohorts." National Center for Education Evaluation and Regional Assistance. Available from: ED Pubs. P.O. Box 1398, Jessup, MD 20794-1398. Tel: 877-433-7827; Web site: http://ies.ed.gov/ncee/pubs/. https://eric.ed.gov/?id=ED504657.

Cassidy, Jack, Evan Ortlieb, and Stephanie Grote-Garcia. 2020. “What's Hot in Literacy: New Topics and New Frontiers Are Abuzz." Literacy Research and Instruction, October, 1-12.

Castles, Anne, Kathleen Rastle, and Kate Nation. 2018. “Ending the Reading Wars : Reading Acquisition From Novice to Expert." Psychological Science in the Public Interest: A Journal of the American Psychological Society 19 (1): 5-51.

Cheung, Alan C. K., and Robert E. Slavin. 2011. "The Effectiveness of Education Technology for Enhancing Reading Achievement : A Meta-Analysis." Best Evidence Encyclopaedia 97 
(January): 1-48.

- - - 2013. "Effects of Educational Technology Applications on Reading Outcomes for Struggling Readers: A Best-Evidence Synthesis." Reading Research Quarterly 48 (3): 277-99. Christ, Tanya, Poonam Arya, and Yu Liu. 2018. “Technology Integration in Literacy Lessons: Challenges and Successes." Literacy Research and Instruction 00 (00): 1-18.

Coltheart, Max, Kathleen Rastle, Conrad Perry, Robyn Langdon, and Johannes C. Ziegler. 2001. “DRC: A Dual Route Cascaded Model of Visual Word Recognition and Reading Aloud." Psychological Review 108 (1): 204-56.

Donnelly, Patrick M., K. Larson, T. Matskewich, and J. D. Yeatman. 2020. “Annotating Digital Text with Phonemic Cues to Support Decoding in Struggling Readers." PloS One in review. Drummond, Kathryn, Marjorie Chinen, and Teresa Garcia Duncan. 2011. "Impact of the Thinking Reader ${ }^{\circledR}$ Software Program on Grade 6 Reading Vocabulary , Comprehension , Strategies , and Motivation." Ncee 2010-4035, 184.

Eagleton, Maya B., and Elizabeth Dobler. 2007. "Reading the Web." Strategies for Internet Inquiry. Ehri, Linnea C. 1995. "Phases of Development in Learning to Read Words by Sight." Journal of Research in Reading 18 (2): 116-25.

- - - 2014. "Orthographic Mapping in the Acquisition of Sight Word Reading, Spelling Memory, and Vocabulary Learning." Scientific Studies of Reading: The Official Journal of the Society for the Scientific Study of Reading 18 (1): 5-21.

- - - 2020. "The Science of Learning to Read Words: A Case for Systematic Phonics Instruction." Reading Research Quarterly 55 (S1): 175.

Ehri, Linnea C., Simone R. Nunes, Dale M. Willows, Barbara Valeska Schuster, Zohreh Yaghoub-Zadeh, and Timothy Shanahan. 2001. "Phonemic Awareness Instruction Helps Children Learn to Read: Evidence From the National Reading Panel's Meta-Analysis." Reading Research Quarterly 36 (3): 250-87.

Elbeheri, Gad, and John Everatt. 2007. "Literacy Ability and Phonological Processing Skills amongst Dyslexic and Non-Dyslexic Speakers of Arabic." Reading and Writing 20 (3): 27394.

Erickson, G. C., K. C. Foster, D. F. Foster, J. K. Torgesen, and S. Packer. 1992. “DaisyQuest.” Scotts Valley, CA: Great Wave Software.

Faul, Franz, Edgar Erdfelder, Albert-Georg Lang, and Axel Buchner. 2007. “G*Power 3: A Flexible Statistical Power Analysis Program for the Social, Behavioral, and Biomedical Sciences." Behavior Research Methods 39 (2): 175-91.

Fernald, Anne, and Patricia Kuhl. 1987. "Acoustic Determinants of Infant Preference for Motherese Speech." Infant Behavior E Development 10 (3): 279-93.

Fletcher, Jack M., G. Reid Lyon, Lynn S. Fuchs, and Marcia A. Barnes. 2018. Learning Disabilities, Second Edition: From Identification to Intervention. Guilford Publications.

Fuchs, Douglas, and Lynn S. Fuchs. 2005. “Peer-Assisted Learning Strategies: Promoting Word Recognition, Fluency, and Reading Comprehension in Young Children." The Journal of Special Education 39 (1): 34-44.

“Fundations®." n.d. Accessed October 29, 2020. https://www.wilsonlanguage.com/programs/fundations/.

Gee, James Paul. 2003. “What Video Games Have to Teach Us about Learning and Literacy." 
Computers in Entertainment 1 (1): 20.

Gilbert, Lisa, Anne Teravainen, Christina Clark, and Sophia Shaw. 2018. "Literacy and Life Expectancy: An Evidence Review Exploring the Link between Literacy and Life Expectancy in England through Health and Socioeconomic Factors." London: National Literacy Trust.

Grant, Amy K., Eileen Wood, Alexandra Gottardo, Mary Ann Evans, Linda Phillips, and Robert S. Savage. 2012. "Assessing the Content and Quality of Commercially Available Reading Software Programs: Do They Have the Fundamental Structures to Promote the Development of Early Reading Skills in Children?" NHSA Dialog 15 (4): 319-42.

Greenfield, Patricia M. 2009. “Technology and Informal Education: What Is Taught, What Is Learned." Science. American Association for the Advancement of Science. https://doi.org/10.1126/science.1167190.

Guernsey, Lisa, and Michael H. Levine. 2015. Tap, Click, Read: Growing Readers in a World of Screens. San Francisco: Jossey-Bass.

Haddad, Laurice, Yael Weiss, Tami Katzir, and Tali Bitan. 2018. “Orthographic Transparency Enhances Morphological Segmentation in Children Reading Hebrew Words." Frontiers in Psychology 8 (JAN): 2369.

Hannon, Peter, and Sue James. 1990. “Parents' and Teachers' Perspectives on Preschool Literacy Development." British Educational Research Journal 16 (3): 259-72.

Harris, J., and M. Hofer. 2009. “Grounded Tech Integration: An Effective Approach Based on Content, Pedagogy, and Teacher Planning." Learning \& Leading with Technology. https://eric.ed.gov/?id=EJ859576.

Hattan, Courtney, and Sarah M. Lupo. 2020. "Rethinking the Role of Knowledge in the Literacy Classroom." Reading Research Quarterly 55 (S1): 66.

Hindman, Annemarie H., Frederick J. Morrison, Carol Mc Donald Connor, and Joseph A. Connor. 2020. "Bringing the Science of Reading to Preservice Elementary Teachers: Tools That Bridge Research and Practice." Reading Research Quarterly 55 (S1): S197-206.

Hoffman, James V., Michiko Hikida, and Misty Sailors. 2020. “Contesting Science That Silences: Amplifying Equity, Agency, and Design Research in Literacy Teacher Preparation." Reading Research Quarterly 55 (S1): S255-66.

Hutchison, Amy, Beth Beschorner, and Denise Schmidt-Crawford. 2012. "Exploring the Use of the iPad for Literacy Learning." The Reading Teacher 66 (1): 15-23.

Kraft, Matthew A., and Manuel Monti-Nussbaum. 2017. "Can Schools Enable Parents to Prevent Summer Learning Loss? A Text-Messaging Field Experiment to Promote Literacy Skills." The Annals of the American Academy of Political and Social Science 674 (1): 85-112.

Kuhl, Patricia K. 2000. "A New View of Language Acquisition." Proceedings of the National Academy of Sciences of the United States of America 97 (22): 11850-57.

Kuhl, P. K., J. E. Andruski, I. A. Chistovich, L. A. Chistovich, E. V. Kozhevnikova, V. L. Ryskina, E. I. Stolyarova, U. Sundberg, and F. Lacerda. 1997. “Cross-Language Analysis of Phonetic Units in Language Addressed to Infants." Science 277 (5326): 684-86.

Larson, Lotta C. 2010. “Digital Readers: The Next Chapter in E-Book Reading and Response." The Reading Teacher 64 (1): 15-22.

Lee, Yuan-Hsuan, Hersh Waxman, Jiun-Yu Wu, Georgette Michko, and Grace Lin. 2013. 
"Revisit the Effect of Teaching and Learning with Technology." Educational Technology $\mathcal{E}$ Society 16 (1): 133-46.

Lovett, Maureen W., Jan C. Frijters, Maryanne Wolf, Karen A. Steinbach, Rose A. Sevcik, and Robin D. Morris. 2017. “Early Intervention for Children at Risk for Reading Disabilities: The Impact of Grade at Intervention and Individual Differences on Intervention Outcomes." Journal of Educational Psychology 109 (7): 889-914.

Lovett, M. W., L. Lacerenza, and S. L. Borden. 2000. “Putting Struggling Readers on the PHAST Track: A Program to Integrate Phonological and Strategy-Based Remedial Reading Instruction and Maximize Outcomes." Journal of Learning Disabilities 33 (5): 458-76.

Lynch, Jacqueline, Jim Anderson, Ann Anderson, and Jon Shapiro. 2006. "Parents' Beliefs About Young Children's Literacy Development And Parents' Literacy Behaviors." Reading Psychology 27 (1): 1-20.

Lyon, G. R., Sally E. Shaywitz, and Bennett A. Shaywitz. 2003. “A Definition of Dyslexia." Annals of Dyslexia 53 (1): 1-14.

Macaruso, Paul, Pamela E. Hook, and Robert McCabe. 2006. “The Efficacy of Computer-Based Supplementary Phonics Programs for Advancing Reading Skills in at-Risk Elementary Students." Journal of Research in Reading 29 (2): 162-72.

Mahfoudhi, Abdessatar, John Everatt, and Gad Elbeheri. 2011. "Introduction to the Special Issue on Literacy in Arabic." Reading and Writing. Springer. https://doi.org/10.1007/s11145-0119306-y.

Mandel Morrow, Lesley, and Elizabeth Asbury. 1999. “What Should We Do About Phonics?" In Best Practices in Literacy Instruction, edited by Linda B. Gambrell, Lesley Mandel Morrow, Susan B. Neuman, and Michael Pressley, 68-89. New York, NY: The Guilford Press.

Maughan, B. 1995. "Annotation: Long-Term Outcomes of Developmental Reading Problems." Journal of Child Psychology and Psychiatry, and Allied Disciplines 36 (3): 357-71.

McDonald Connor, Carol, Shayne B. Piasta, Barry Fishman, Stephanie Glasney, Christopher Schatschneider, Elizabeth Crowe, Phyllis Underwood, and Frederick J. Morrison. 2009. "Individualizing Student Instruction Precisely: Effects of Child $\times$ Instruction Interactions on First Graders' Literacy Development." Child Development 80 (1): 77-100.

McTigue, Erin M., Oddny Judith Solheim, Wendi K. Zimmer, and Per Henning Uppstad. 2020. “Critically Reviewing GraphoGame Across the World: Recommendations and Cautions for Research and Implementation of Computer-Assisted Instruction for Word-Reading Acquisition." Reading Research Quarterly 55 (1): 45-73.

Medler, D. A., and J. R. Binder. 2005. “MCWord: An Orthographic Wordform Database.” 2005. http://www.neuro.mcw.edu/mcword/.

Mesmer, Heidi Anne E., and Thomas O. Williams. 2015. “Examining the Role of Syllable Awareness in a Model of Concept of Word: Findings From Preschoolers." Reading Research Quarterly 50 (4): 483-97.

Messer, David, and Gilly Nash. 2018. "An Evaluation of the Effectiveness of a ComputerAssisted Reading Intervention." Journal of Research in Reading 41 (1): 140-58.

Moats, Louisa C. 1999. "Teaching Reading Is Rocket Science: What Expert Teachers of Reading Should Know and Be Able To Do." American Federation of Teachers. https://eric.ed.gov/?id=ED445323. 
National Assessment of Educational Progress. 2019. “NAEP Report Card: Reading.” U.S. Department of Education. https://www.nationsreportcard.gov/reading?grade=4 .

National Reading Panel. 2000. "Teaching Children to Read: An Evidence-Based Assessment of the Scientific Research Literature on Reading and Its Implications for Reading Instruction." Washington, D.C.: NICHD.

Noguerón-Liu, Silvia. 2020. “Expanding the Knowledge Base in Literacy Instruction and Assessment: Biliteracy and Translanguaging Perspectives From Families, Communities, and Classrooms." Reading Research Quarterly 55 (S1): 355.

Ok, Min Wook, and Kavita Rao. 2019. “Digital Tools for the Inclusive Classroom: Google Chrome as Assistive and Instructional Technology." Journal of Special Education Technology 34 (3): 204-11.

Petscher, Yaacov, Sonia Q. Cabell, Hugh W. Catts, Donald L. Compton, Barbara R. Foorman, Sara A. Hart, Christopher J. Lonigan, et al. 2020. "How the Science of Reading Informs 21st-Century Education." Reading Research Quarterly 55: 267-82.

Phillips Galloway, Emily, Janna Brown McClain, and Paola Uccelli. 2020. "Broadening the Lens on the Science of Reading: A Multifaceted Perspective on the Role of Academic Language in Text Understanding." Reading Research Quarterly 55 (S1): S331-45.

Rabiner, David L., Desiree W. Murray, Ann T. Skinner, and Patrick S. Malone. 2010. “A Randomized Trial of Two Promising Computer-Based Interventions for Students with Attention Difficulties." Journal of Abnormal Child Psychology 38 (1): 131-42.

Richardson, Ulla, and Heikki Lyytinen. 2014. “The GraphoGame Method: The Theoretical and Methodological Background of the Technology-Enhanced Learning Environment for Learning to Read." Human Technology: An Interdisciplinary Journal on Humans in ICT Environments 10 (1): 39-60.

Ronimus, Miia, and Heikki Lyytinen. 2015. “Is School a Better Environment Than Home for Digital Game-Based Learning? The Case of GraphoGame." Human Technology: An Interdisciplinary Journal on Humans in ICT Environments 11 (2): 123-47.

Scanlon, Donna M., and Kimberly L. Anderson. 2020. “Using Context as an Assist in Word Solving: The Contributions of 25 Years of Research on the Interactive Strategies Approach." Reading Research Quarterly 55 (S1): 73.

Schiff, Rachel, and Elinor Saiegh-Haddad. 2018. “Development and Relationships Between Phonological Awareness, Morphological Awareness and Word Reading in Spoken and Standard Arabic." Frontiers in Psychology 9 (APR): 356.

Scott, Jerrie C., and Cheryl D. Marcus. 2014. "Emergent Literacy: Home--School Connections.” In Literacy in African American Communities, 105-26. Routledge.

Seidenberg, Mark S. 2005. "Connectionist Models of Word Reading." Current Directions in Psychological Science 14 (5): 238-42.

- - - 2017. Language at the Speed of Sight: How We Read, Why so Many Can't, and What Can Be Done about It. New York, NY: Basic Books.

Seidenberg, Mark S., Matt Cooper Borkenhagen, and Devin M. Kearns. 2020. "Lost in Translation? Challenges in Connecting Reading Science and Educational Practice." Reading Research Quarterly 55 (S1): S119-30.

Seward, R., B. O’Brien, A. D. Breit-Smith, and B. Meyer. 2014. “Linking Design Principles with 
Educational Research Theories to Teach Sound to Symbol Correspondence with Multisensory Type." Visible Language 48 (3): 87-108.

Shany, Michal, Amalia Bar-On, and Tami Katzir. 2012. "Reading Different Orthographic Structures in the Shallow-Pointed Hebrew Script: A Cross-Grade Study in Elementary School." Reading and Writing 25 (6): 1217-38.

Share, D. L. 1995. "Phonological Recoding and Self-Teaching: Sine qua Non of Reading Acquisition." Cognition 55 (2): 151-218; discussion 219-26.

Snowling, Margaret J. 2004. "The Science of Dyslexia: A Review of Contemporary Approaches." In The Study of Dyslexia, edited by Martin Turner and John Rack, 77-90. Boston, MA: Springer US.

Soe, Kyaw, Stan Koki, and Juvenna M. Chang. 2000. “Effect of Computer-Assisted Instruction (CAI) on Reading Achievement: A Meta-Analysis." Pacific Resources for Education and Learning, June. https://eric-ed-gov.offcampus.lib.washington.edu/?id=ED443079.

Solheim, Oddny Judith, Jan C. Frijters, Kjersti Lundetræ, and Per Henning Uppstad. 2018. "Effectiveness of an Early Reading Intervention in a Semi-Transparent Orthography: A Group Randomised Controlled Trial." Learning and Instruction 58 (July 2017): 65-79.

Stetter, Maria Earman, and Marie Tejero Hughes. 2015. “Computer-Assisted Instruction to Enhance the Reading Comprehension of Struggling Readers: A Review of the Literature." Journal of Special Education Technology 25 (4): 1-16.

Tare, Medha, Alison R. Shell, and Scott R. Jackson. 2020. "Student Engagement with EvidenceBased Supports for Literacy on a Digital Platform." Journal of Research on Technology in Education 0 (0): 1-11.

Taylor, D. Bruce, Laura K. Handler, Erin FitzPatrick, and Colleen E. Whittingham. 2020. “The Device in the Room: Technology's Role in Third Grade Literacy Instruction." Journal of Research on Technology in Education, October. https://doi.org/10.1080/15391523.2020.1747577.

The Annie E. Casey Foundation. 2013. "Early Warning Confirmed: A Research Update on Third-Grade Reading." https://www.aecf.org/resources/early-warning-confirmed/. The MathWorks, Inc. 2017. MATLAB Statistics and Machine Learning Toolbox. Natick, MA, USA. Tichnor-Wagner, Ariel, Justin D. Garwood, Mary Bratsch-Hines, and Lynne Vernon-Feagans. 2016. "Home Literacy Environments and Foundational Literacy Skills for Struggling and Nonstruggling Readers in Rural Early Elementary Schools." Learning Disabilities Research $\mathcal{E}$ Practice: A Publication of the Division for Learning Disabilities, Council for Exceptional Children 31 (1): 6-21.

Torgesen, Joseph K., Richard K. Wagner, Carol A. Rashotte, Jeannine Herron, and Patricia Lindamood. 2010. "Computer-Assisted Instruction to Prevent Early Reading Difficulties in Students at Risk for Dyslexia: Outcomes from Two Instructional Approaches." Annals of Dyslexia 60 (1): 40-56.

Vaughn, Sharon, Jack M. Fletcher, David J. Francis, Carolyn A. Denton, Jeanne Wanzek, Jade Wexler, Paul T. Cirino, Amy E. Barth, and Melissa A. Romain. 2008. "Response to Intervention with Older Students with Reading Difficulties." Learning and Individual Differences 18 (3): 338-45.

Vellutino, Frank R., and Donna M. Scanlon. 2002. "The Interactive Strategies Approach to Reading Intervention." Contemporary Educational Psychology 27 (4): 573-635. 
Wanzek, Jeanne, Sharon Vaughn, Nancy K. Scammacca, Kristina Metz, Christy S. Murray, Greg Roberts, and Louis Danielson. 2013. “Extensive Reading Interventions for Students With Reading Difficulties After Grade 3." Review of Educational Research 83 (2): 163-95.

Washington, Julie A. 2001. "Early Literacy Skills in African-American Children: Research Considerations." Learning Disabilities Research E Practice: A Publication of the Division for Learning Disabilities, Council for Exceptional Children 16 (4): 213-21.

Weiss, Yael, Tami Katzir, and Tali Bitan. 2015a. “The Effects of Orthographic Transparency and Familiarity on Reading Hebrew Words in Adults with and without Dyslexia." Annals of Dyslexia 65 (2): 84-102.

- - - 2015b. "Many Ways to Read Your Vowels--Neural Processing of Diacritics and Vowel Letters in Hebrew." NeuroImage 121 (November): 10-19.

Willis, Arlette Ingram. 2019. "Race, Response to Intervention, and Reading Research." Journal of Literacy Research: JLR 51 (4): 394-419.

Wise, Barbara W., and Richard K. Olson. 1995. "Computer-Based Phonological Awareness and Reading Instruction." Annals of Dyslexia 45 (1): 97-122.

- - - 1998. "Studies of Computer-Aided Remediation for Reading Disabilities." In Reading and Spelling: Development and Disorders, edited by Charles Hulme and R. M. Joshi, 473-87. Mahwah, NJ: Lawrence Erlbaum Associates, Inc.

Wolf, Maryanne. 2007. Proust and the Squid: The Story and Science of the Reading Brain. New York: HarperCollins.

- - - 2018. Reader, Come Home. New York, NY: HarperCollins.

Wolf, Maryanne, Stephanie Gottwald, Cynthia Breazeal, Tinsley Galyean, and Robin Morris. 2017. "'I Hold Your Foot:' Lessons from the Reading Brain for Addressing the Challenge of Global Literacy." In Children and Sustainable Development, 225-38. Cham: Springer International Publishing.

Wolf, Maryanne, Stephanie Gottwald, Tinsley Galyean, Robin Morris, and Cynthia Breazeal. 2014. "The Reading Brain, Global Literacy, and the Eradication of Poverty." In Proceedings of Bread and Brain, Education and Poverty, 1-22. Vatican City: Pontifical Academy of Sciences.

Zuckerman, Barry. 2017. “A Guiding Framework for Considering Touchscreens in Children under Two." International Journal of Child-Computer Interaction 12 (April): 46-49. 


\section{Acknowledgments:}

We would like to thank the research participants and their families for making this project possible. This work was funded by NSF BCS 1551330, NIH NICHD R01HD09586101, NICHD R21HD092771, Microsoft Research Grants and a Jacobs Foundation Research Fellowship to J.D.Y.

\section{Author Contributions:}

P.M.D., P.K.K. and J.D.Y. designed the study. P.M.D. and L.G. collected the data. P.M.D. analyzed the data. K.L., T.M., and P.L. provided software and resources for execution of the study. All authors contributed to the design of the intervention technology, as well as contributed to the manuscript. The funders, including Microsoft Corporation, had no role in study design, data collection and analysis, interpretation, decision to publish, or preparation of the manuscript. Three authors [K.L., T.M and P.L.], are employed by Microsoft Corporation. Microsoft Corporation provided support in the form of salaries for authors [K.L., T.M and P.L.] and research materials but did not have any additional role in the study design, data collection and analysis, interpretation, decision to publish, or preparation of the manuscript. 